\title{
Behandelmogelijkheden bij GATOR1-gerelateerde epilepsie
}

Meer dan de helft van de patiënten met een GATORI pathogene variant heeft therapieresistente epilepsie. Als een focale corticale dysplasie aanwezig is, of met uitgebreid prechirurgisch onderzoek de epileptogene zone duidelijk te identificeren en afgrensbaar blijkt, kan chirurgische resectie een optie zijn. Echter, voor een deel van deze patiënten ontbreken vooralsnog effectieve therapieën. Voor hen kan mTOR remming een veelbelovende vorm van precisiebehandeling zijn, die met een 'n-of-I' studie kan worden onderzocht.

De afgelopen decennia is in toenemende mate duidelijk geworden dat genetische factoren een belangrijke rol spelen in de etiologie van zowel focale als gegeneraliseerde epilepsie. Dankzij de introductie in het DNA-onderzoek van next generation sequencing, raakte het identificeren van een genetisch basis voor zowel non-structurele als structurele epilepsie in een stroomversnelling (Helbig \& Abou Tayoun, 2016). Het vaststellen van een monogene oorzaak van epilepsie biedt mogelijkheden voor zogenaamde precision medicine, dat wil zeggen behandeling die specifiek is afgestemd op één bepaald individu. Hiernavolgend worden twee verschillende benaderingen van precision medicine besproken bij GATORI-gerelateerde epilepsie, namelijk epilepsiechirurgie en 'mammalian target of rapamycin' (mTOR) remming in een 'n-of-I' trial benadering.

\section{Epilepsie en de mTOR-signaalroute}

De mTOR-signaalroute speelt een rol bij essentiële biologische processen zoals lipiden- en eiwitsynthese, celgroei, -overleving, -proliferatie en -migratie (figuur I), en daarmee bij de ontwikkeling en aanleg van de hersenen. (Crino 20I6; D'Gama et al. 2015) Daarnaast speelt mTOR een belangrijke rol in de plasticiteit van neuronale synapsen. (Lasarge \& Danzer 20I4) Disregulatie van de mTOR-signaalroute bij epilepsie werd voor het eerst beschreven bij tubereuze sclerose complex (TSC), met mutaties in de genen TSCi en TSC2.(Crino 20r6) Andere belangrijke genen binnen de mTOR-signaalroute zijn de genen gerelateerd aan $\mathrm{PIK}_{3}$ en AKT (PIK3CA, PIK3 R1, PIK3 R2 en AKT3) en de GATORI genen (DEPDC 5 , NPRL2, NPRL3). Het GATORI-compex is een directe negatieve regulator van mTOR complex I (mTORCI), zodat loss-of-function van GATORI tot overactiviteit van mTORCi leidt. (Bar-Peled et al. 20I3; Weckhuysen et al. 20I6) Als gevolg hiervan, raakt mTORCI ongevoelig voor de moleculaire mechanismen die celgroei, overleving, proliferatie en migratie reguleren.
Mutaties in de bovengenoemde genen zijn veelal, maar niet altijd, geassocieerd met malformaties van de corticale ontwikkeling, zoals tubers, focale corticale dysplasie (FCD) en hemimegalencefalie (Baldassari et al. 20r9; Baulac et al., 20I5). Soms is een dergelijke aanlegstoornis zichtbaar met MRI, soms echter ook niet. In een groep van zeven patiënten met een mutatie in één van de GATORI genen, werden bij drie patiënten geen MRI-afwijkingen aangetoond, terwijl bij histologisch onderzoek wel een FCD geïdentificeerd werd (Baulac et al., 2015). Deze discrepantie zou verklaard kunnen worden door de hypothese dat GATORI gerelateerde mutaties ook microscopische corticale afwijkingen kunnen veroorzaken, die op MRI niet zichtbaar zijn.

\section{Beleid bij GATORI-gerelateerde epilepsie}

Bij patiënten met GATORI-gerelateerde focale epilepsie worden gemiddeld vier anti-epileptica geprobeerd, en ongeveer $54-65 \%$ van de patiënten ontwikkelt een therapieresistente epilepsie (Baldassari et al., 20I9). Vooralsnog is het huidige beleid bij therapieresistente GATORI-epilepsie afhankelijk van de aanwezigheid van structurele afwijkingen op de MRI. Als een FCD gedetecteerd wordt, vindt preoperatieve evaluatie plaats met als uiteindelijk doel te beoordelen of resectie van de epilepsiebron mogelijk is. Uit onderzoek blijkt dat 6o\% van de patiënten die kandidaat zijn voor operatie, hierna aanvalsvrij (Engel I) is en $20 \%$ enkel sporadische belemmerende aanvallen ervaart (Engel II) (Baldassari et al., 20I9).

Bij patiënten zonder structurele beeldvormende afwijking(en), maar met een heel consistente semiologie en monofocale EEG-afwijkingen kan het prechirurgisch onderzoek worden uitgebreid om met aanvullende technieken een hypothese te vormen over een mogelijke enkelvoudige epileptogene bron. Hiermee kan worden nagegaan of de epileptogene zone duidelijk is te identificeren en afgrens- 


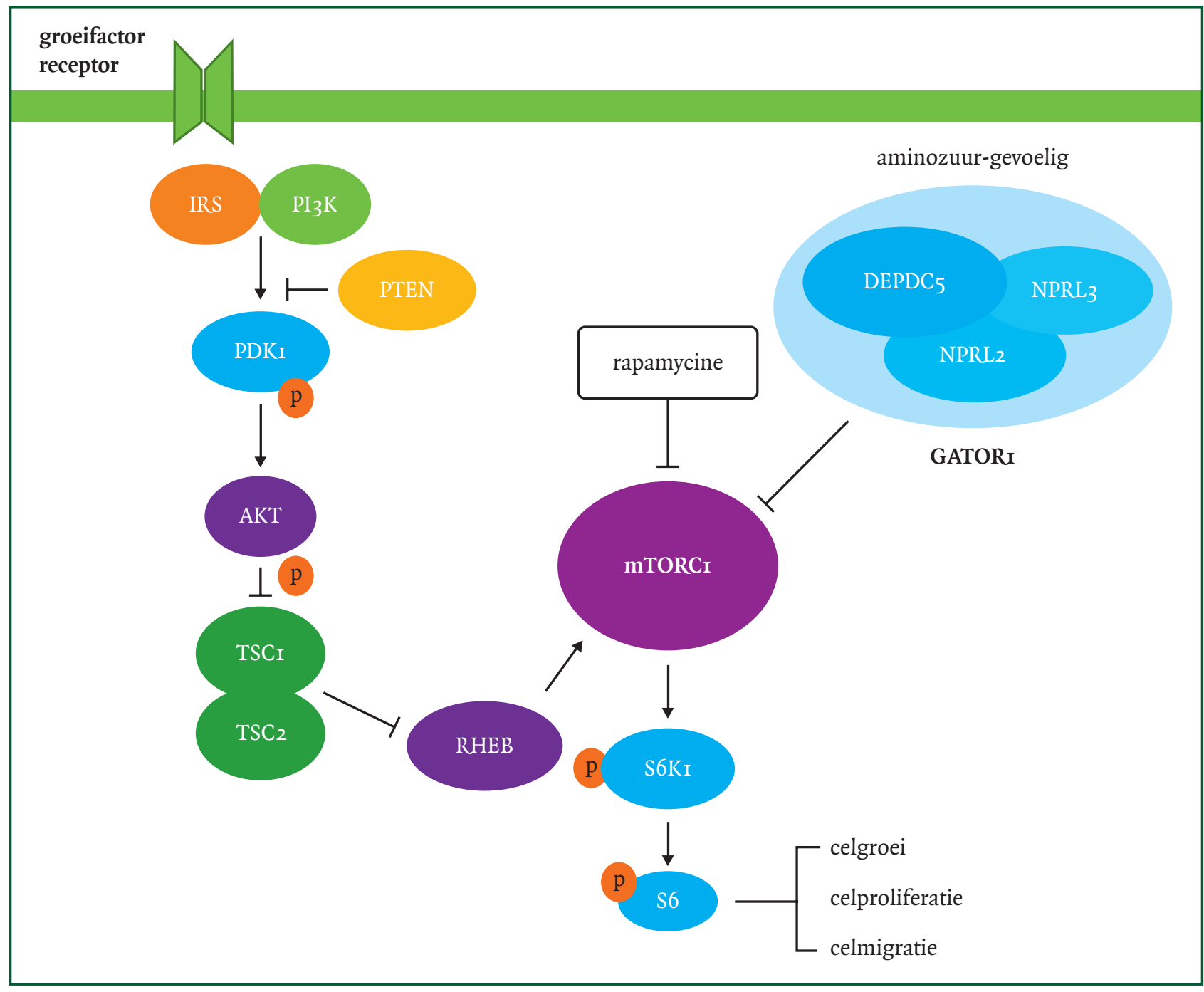

Figuur I Schematische weergave van mTORCI-GATORI signaalroute. Met behulp van een pijl wordt een activerend mechanisme aangegeven en een lijn-stopstreep geeft een inhiberend mechanisme aan. [N.B. Figuur is overgenomen uit Crino (2016) en hier in aangepaste vorm weergegeven]. Het mTOR complex 1 wordt via verschillende mechanismen gereguleerd. Hier worden enkel de groeifactor route en de aminozuur-gevoelige route afgebeeld. In de groeifactor route zet phosphatidylinositol 3-kinase (PI $3 \mathrm{~K}$ ) een fosfolyseringscascade op gang als respons op groeifactor stimulatie. Dit leidt tot activatie van de alfa-threonine kinase (AKT). AKT heeft een direct remmend effect op tuberin (TSC2). Door de inhiberende werking van TSC op RHEB kan mTORC1 geactiveerd worden. GATOR1 is betrokken bij de aminozuur-respons route. GATOR1 is een complex bestaande uit DEPDC5 (DEP domain-containing protein 5), en NPRL2 en NPRL3 (nitrogen permease regulator-like protein 2 en 3). Bij een te kort aan aminozuren, wordt GATOR1 actief en heeft dit complex een remmende werking op mTORC1. Bij normale aminozuurconcentraties zou er geen inhibitie door het GATOR1 complex plaatsvinden en zou mTORC1 actief zijn. Wanneer mTORC1 actief is, zorgt deze via fosforylering van de S6K1 en S6 eiwitten voor bevordering van celgroei, celproliferatie en celmigratie. Een loss-of-function variant van een van de GATOR1 complex eiwitten, kan overactiviteit van de mTORC1 veroorzaken. Medicamenteuze toediening van rapamycine zorgt voor mTORC1 inhibitie.

baar is, waarmee resectie een effectieve behandelmogelijkheid wordt.

Preoperatieve genetische diagnostiek

Vanuit het perspectief van epilepsiechirurgie, heeft precision medicine ten doel om zo vroeg mogelijk onderscheid te maken tussen patiënten die wel of juist geen geschikte kandidaten zijn voor epilepsiechirurgie. Verschillende studies hebben laten zien dat moleculair genetische diagnostiek in de prechirurgische evaluatiefase kan bijdragen aan dit onderscheid, óók als de MRI-bevindingen hierbij in aanmerking worden genomen. Uit een systematisch onderzoek van de literatuur bleek dat epilepsiechirurgie bijna nooit effectief was als de epilepsie verklaard kon worden door mutaties van ionkanaal-genen en door genen betrokken bij synaptische transmissie (Stevelink et al., 20I8). Epilepsiechirurgie was daarentegen juist relatief vaak succesvol bij patiënten met mutaties in genen binnen de mTOR-signaalroute, zeker als deze gepaard gingen met een structurele focale MRI-afwijking, zoals een FCD. Niet elke patiënt met epilepsie door een mutatie in één van de mTOR-genen komt echter in aanmerking voor epilepsie- 
chirurgie. Gezien het hoge percentage patiënten dat therapieresistent is, is er daarom behoefte aan andere effectieve behandelopties.

\section{Medicamenteuze precisiebehandelingen}

Het herkennen van de rol van pathogene varianten in de genen voor de mTOR-signaalroute heeft geleid tot het gebruik van mTOR-remmers, rapamycine (sirolimus) en de moleculaire analoog everolimus, als precisiebehandeling bij TSC-gerelateerde ziektebeelden. Vanwege de kenmerken van GATORI, zouden mTOR-remmers ook als experimentele vorm van precision medicine bij GATORI-gerelateerde epilepsie toegepast kunnen worden.

Het gebruik van mTOR-remmers als precision treatment bij epilepsie biedt een medicamenteuze behandeloptie met een ziekte-modificerende effect. Dit houdt in dat het gebruik van mTOR remmers de pathologische gevolgen van de bestaande mutatie kunnen verbeteren. Eerder onderzoek liet een overmatige MTORCI activiteit zien in verwijderd hersenweefsel van TSC patiënten (Ruppe et al., 20I4) en patiënten met GATORI-varianten, met of zonder structurele afwijkingen (Weckhuysen et al., 20I6). Rapamycine en everolimus kunnen mTORCr activiteit direct remmen en hierdoor de dynamische processen in en rondom een corticale aanlegstoornis beïnvloeden. De gunstige effecten bij TSC waren reeds bekend, maar onlangs bleek dat ook bij GATORI-gerelateerde epilepsie (in een preklinisch DEPDC $_{5}$ loss-of-function model) het chronisch gebruik van een mTOR-remmer leidde tot verminderde mTORCI activiteit in hersenweefsel en verbetering van epilepsiegerelateerde mortaliteit (Yuskaitis et al., 20I9).

mTOR-remmers bieden daarom waarschijnlijk een nieuwe medicamenteuze behandelmogelijkheid bij patiënten met GATORI-gerelateerde, refractaire epilepsie. In de kliniek zou dit toegepast kunnen worden bij patiënten die (nog) niet in aanmerking komen voor epilepsiechirurgie, of bij wie aanvalsvrijheid na een chirurgische ingreep niet bereikt is. Echter, vooralsnog ontbreekt wetenschappelijk bewijs om deze medicamenteuze optie in de klinische praktijk op een veilige manier routinematig te implementeren.

\section{' $\mathrm{N}$-of-I' studies met precisiebehandelingen} GATORI-gerelateerde epilepsie is een zeldzame ziekte. Het betreft een heterogene patiëntengroep waarbij de debuutleeftijd van de epilepsie, het ziektebeloop en de semiologie van aanvallen erg kunnen variëren. Het verrichten van grote klinische studies wordt hierdoor sterk bemoeilijkt en het verkrijgen van een hoog niveau van wetenschappelijk bewijs voor het gebruik van mTORremmers bij patiënten met GATORI-gerelateerde epilepsie is een uitdaging.
Tot op heden is er maar één publicatie verschenen over een kind van drie maanden met een NPRL3 (loss-of-function) variant en refractaire epilepsie, die met rapamycine behandeld werd. (Vawter-Lee et al., 2019) Op basis van het biologische mechanisme kunnen mTOR-remmers off-label als experimentele therapie worden gegeven. Hoewel dit als een innovatieve en veelbelovende therapeutische optie wordt gezien, is er geen duidelijkheid over de exacte indicaties, het behandelplan en de aangewezen monitoring voor klinisch gebruik bij GATORI-gerelateerde epilepsie. Daarnaast gaat mTOR-remming gepaard met bekende systemische en metabole bijwerkingen. Daarom dient de effectiviteit van mTOR-remmers in deze doelgroep geëvalueerd te worden en te worden afgewogen tegen de bijwerkingen. Daarnaast leidt het off-label voorschrijven tot problemen met bekostiging omdat de behandeling door zorgverzekeraar niet vergoed wordt als het benodigde wettenschappelijk bewijs ontbreekt. Een gestandaardiseerde en veilige manier om off-label 'therapie op proef' toe te passen bij zeldzame ziekten ontbreekt vooralsnog. Daarom wordt er bij het UMCU Brain Center momenteel een design voor individuele klinische studies, oftewel 'n-of-I' studies ontwikkeld. Met n-of-I studies is het hoogste niveau van wetenschappelijk bewijs te bereiken voor effectiviteit en veiligheid op individueel niveau. N-of-I studies zijn klinische studies met één enkele patiënt, waarbij de patiënt gedurende herhaalde afgebakende periodes een controle interventie of een actieve interventie ondergaat (figuur 2). Het idee van n-of-I studies is gebaseerd op de dubbelblinde, gerandomiseerde gouden standaard van klinische studies, maar dan toegepast op de individuele patiënt. Hiermee wordt de uitdaging van kleine patiëntenaantallen - inherent aan een zeldzame, heterogene ziekte - omzeild, terwijl de methodologische kwaliteit en statistische nauwkeurigheid behouden blijven. De studieopzet kan afgestemd worden op de specifieke situatie van een individuele patiënt, ten aanzien van bijvoorbeeld aanvalsfrequentie en comorbiditeit, en op de kenmerken van de in dit geval medicamenteuze behandeling. N-of-I studies zijn met name geschikt voor chronische aandoeningen met een meetbare uitkomst waarbij de behandeling een relatief snelle werking heeft. N-of-I studies zijn in het verleden zelden toegepast bij epilepsieonderzoek (Privitera et al., I994). Bij patiënten met refractaire epilepsie kan deze studieopzet een geschikte methode zijn om de effectiviteit en veiligheid van een behandeling te evalueren (Margolis \& Giuliano 20r9). Bovendien kan door aggregatie van vele n-of-I studies ook wetenschappelijk bewijs voor de algehele effectiviteit van nieuwe behandelingen worden geleverd.

\section{Conclusie}

GATORI-gerelateerde epilepsie is een zeldzame aandoe- 


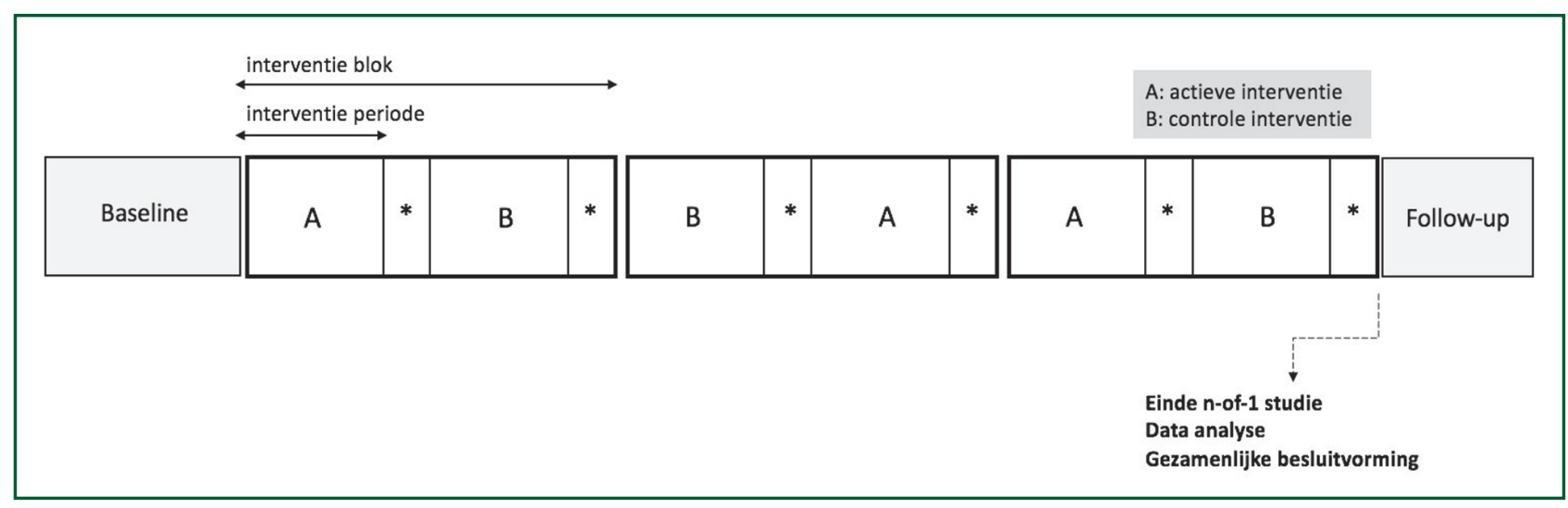

Figuur 2: Schematische weergave van een 'n-of-I' studie. Een n-of-1 studie bestaat uit een baseline periode, herhaaldelijk periodes van interventies die in blokken kort na elkaar plaats vinden, en een gezamenlijk besluitvorming en follow-up periode. Concreet doorloopt de individuele patiënt een aantal blokken die bestaan uit (minimaal) een periode met de actieve interventie (A) en een periode met controle interventie (B, placebo; standaard zorg; andere interventie ter vergelijking). Door deze periodes te doorlopen fungeert de patiënt als eigen controle. De volgorde van de periodes binnen een blok kan willekeurig bepaald worden. Tussen de periodes kan er een wash-out periode ( ${ }^{*}$ ) zonder interventie plaats vinden om de effecten van A of B te elimineren of 'uit te wassen'. Na afloop van de studieblokken wordt de data statistisch geanalyseerd en vindt een gezamenlijk besluitvorming plaats, waar behandeleffectiviteit met betrekking tot ziekteverloop en individuele doelen bepaald kan worden en een follow-up plan voor de patiënt opgesteld wordt. De individuele patiënt staat dus centraal en behandeleffectiviteit wordt voor die individuele patiënt beoordeeld.

ning waarbij 54-65\% van de patiënten therapieresistente epilepsie ontwikkelt (Baldassari et al., 20I9). Het beschrijven en karakteriseren van het GATORI-gerelateerde epilepsie fenotype, en het gebruik van moleculaire diagnostiek, kan leiden tot een belangrijke vooruitgang in de behandelmogelijkheden bij deze patiënten. Hoewel epilepsiechirurgie bij veel GATORI-gerelateerde refractaire epilepsiepatiënten voor aanvalsvrijheid kan zorgen, ontbreekt het bewijs voor nieuwe medicamenteuze behandelingen van patiënten die niet voor epilepsiechirurgie in aanmerking komen, of bij wie ondanks chirurgische resectie geen aanvalscontrole wordt bereikt. Op basis van de biologische gevolgen van de GATORI loss-of-function varianten, bieden mTOR-remmers een mogelijkheid tot behandeling op maat. De n-of-I studie leent zich ervoor om op een veilige manier individuele studies naar de effectiviteit van mTORremmers bij patiënten te verrichten en het hoogste niveau van wetenschappelijk bewijs te kunnen behalen.

\section{Referenties}

Helbig, I. \& Abou Tayoun, A. N. (2016) Understanding genotypes and phenotypes in epileptic encephalopathies. Mol. Syndromol. 7, I72-I8I.

D'Gama, et al. (2015) mTOR Pathway Mutations Cause Hemimegalencephaly and Focal Cortical Dysplasia. Ann. Neurol. 77, 720-725.

Crino, P. B. (2016) The mTOR signalling cascade: Paving new roads to cure neurological disease. Nat. Rev. Neurol. I2, 379-392.

Lasarge, C. L. \& Danzer, S. C. (20I4) Mechanisms regulating neuronal excitability and seizure development following mTOR pathway hyperactivation. Front. Mol. Neurosci. 7, I-I5.

Weckhuysen, S, et al. (2016) Involvement of GATOR complex genes in familial focal epilepsies and focal cortical dysplasia. Epilepsia 57, 994-1003.

Bar-Peled, L. et al. (2013) A tumor suppressor complex with GAP activity for the Rag GTPases that signal amino acid sufficiency to mTORCI. Science (80-.). 340, IIoo-IIo6.

Baulac, S; Ishida, S; Marsan, E, et al. (20I5) Familial Focal Epilepsy with Focal Cortical Dysplasia Due to DEPDC 5 Mutations. Ann. Neurol. 77, 675-683 (2015).

Baldassari, S, et al. (20I9) The landscape of epilepsyrelated GATORI variants. Genet. Med. 2I, 398-408.

Ruppe, V, et al. (20I4) Developmental brain abnormalities in tuberous sclerosis complex: A comparative tissue analysis of cortical tubers and perituberal cortex. Epilepsia 55, 539-550.

Yuskaitis, C. J, et al. (2019) Chronic mTORCr inhibition rescues behavioral and biochemical deficits resulting from neuronal Depdc5 loss in mice. Hum. Mol. Genet. 28, 2952-2964.

Vawter-Lee, M., Franz, D. N., Fuller, C. E, et al. (20rg) Clinical Letter: A case report of targeted therapy with sirolimus for NPRL3 epilepsy. Seizure 73, 43-45.

Loiseau, P. (I999) Review of controlled trials of gabitril (tiagabine): A clinician's viewpoint. Epilepsia 40.

Privitera, MD, et al. (I994) Dezinamide for Partial Seizures: Results of an n-of-I Trial Design. Neurology 44, I453-58. Margolis, A. \& Giuliano, C. (20I9) Making the switch: From case studies to N-of-I trials. Epilepsy Behav. Reports I 2,100336 . 